\title{
REDES TRANSNACIONALES COMO ESTRATEGIA MIGRATORIA. ARGELINOS EN LA RIBERA DEL EBRO
}

\author{
TRANSNATIONAL NETWORKS AS A MIGRATION STRATEGY. \\ IALGERIANS IN THE EBRO RIVERSIDE
}

\author{
Anna Mata Romeu \\ Universidad de Lérida. España/Spain \\ annamata@geosoc.udl.cat
}

Recibido/Received: 07/07/2015

Modificado/Modified: 28/09/2015

Aceptado/Accepted: 04/10/2015

\section{RESUMEN}

Las redes pueden servir para amortiguar el peso que tienen sobre los migrantes los costes y la ruptura vital que supone la inmigración; determinar, hasta cierto punto, quiénes son los que emigran de las comunidades y las familias; influir en la selección de los lugares de destino y de origen; mantener los vínculos del migrante con la sociedad de origen y condicionar la integración de los migrantes en la sociedad de destino. Nuestra premisa es que las redes existen y cobran importancia, dentro del proyecto migratorio, tanto en el trayecto como en el asentamiento; pero su uso e intensidad es tremendamente dispar y distinto, según nos refiramos a unas u otras comunidades de inmigrantes. Profundizaremos en las formas en que las utilizan en el colectivo de procedencia argelina asentado en España, a raíz de trabajos de campo desarrollados en la Comunidad Foral Navarra (España) entre los años 2002 y 2013.

\section{PALABRAS CLAVE}

Redes migratorias, transnacionalismo, migraciones internacionales.

\section{SUMARIO}

1. 1. Redes migratorias y su funcionalidad. 2. Llegada y distribución de argelinos en España. 3. Estrategias de llegada y asentamiento. 3.1. Redes sociales desde Argelia que facilitan la emigración.

3.2. Redes que facilitan el asentamiento en el país de destino. 3.3. Redes relacionales en base a las creencias religiosas. 4. Reflexiones finales. Bibliografia.

\begin{abstract}
Networks can serve to cushion the weight they have on migrants living costs and disruption involved in immigration; determine, to some extent, who are those who migrate from communities and families; influence the selection of the places of destination and origin; maintaining links with society migrant origin and condition of the integration of migrants into the host society. Our premise is that networks exist and become important within the migration project, both in the way as in the settlement; but its use and intensity is extremely disparate and different, as we refer to one or another immigrant community. We delve into the ways in which they use in the group of Algerian origin settled in Spain, following field work developed in the Autonomous Community of Navarre (Spain) between 2002 and 2013.
\end{abstract}

\section{KEYWORDS}

Migration networks, transnationalism, international migration. 


\section{CONTENTS}

1. Migration networks and functionality. 2. Arrival and distribution of Algerian in Spain. 3. Strategies for arrival and settlement. 3.1. Social networks from Algeria to facilitate emigration. 3.2. Networks that facilitate the settlement in the country. 3.3. Relational networks based on religious beliefs. 4. Final reflections. References.

\section{REDES MIGRATORIAS Y SU FUNCIONALIDAD}

Los hechos migratorios, dada su complejidad, necesitan para un análisis más profundo tener en cuenta las redes sociales, que permiten considerar las migraciones como procesos, puesto que se producen interconexiones en todos los momentos o episodios del fenómeno: en el momento de la decisión migratoria, en las circunstancias del desplazamiento y en los movimientos y estrategias que desarrollan los migrantes en su lugar de asentamiento, proceso que es considerado como de variables continúas y no como meras conexiones dicotómicas entre agentes (Massey, 1990). Como sostienen Guarnizo et al. (2003a) la migración no suele ser un proceso individual sino que abarca a núcleos bastante amplios de personas, tanto en el lugar de origen, como el de llegada y en los tramos intermedios. Las redes conectan a los migrantes y sus redes sociales a través del tiempo y del espacio y son de vital importancia en el proceso migratorio.

Las redes, contribuyen a proporcionar alojamiento, trabajo, ayuda en los trámites burocráticos y apoyo en caso de dificultades personales. Estas redes sociales hacen que el proceso migratorio sea más seguro y llevadero para los migrantes y sus familias. Además, los vínculos entre la comunidad migrante y su región de origen pueden mantenerse a lo largo de generaciones; aunque la frecuencia de las visitas al país de origen disminuya, los vínculos familiares y culturales permanecen y se renuevan.

Gurak y Caces (1998) y Castles y Miller (2004), entre otros, sostienen que recurrir a redes de apoyo ha sido siempre la estrategia normal y la más generalizada en todo proceso migratorio, dado que la dinámica de la migración implica la interacción simultánea de la sociedad emisora y receptora y proporcionan una estructura coherente a las poblaciones de migrantes.

Por tanto, una red migratoria no tiene por qué estar fuertemente institucionalizada, sino que puede girar en torno a algún principio subyacente (como el intercambio recíproco $\mathrm{u}$ otras metas comunes compartidas); puede no estar normativamente definida, dado que suele adoptar todo un abanico de formas, desde las más desgajadas a las más institucionalizadas; y requiere de algún tipo de orden interno, a la vez que evoluciona con el tiempo y la propia maduración de las relaciones que se establecen.

Asimismo, estas redes pueden cumplir diversas funciones, si diferenciamos la evolución a corto y a largo plazo. A corto plazo, las redes sirven para amortiguar las duras condiciones de llegada. Pueden facilitan documentos y contactos en destino; amortiguar el choque producido por el abandono del territorio propio y la inmersión en un nuevo mundo de relaciones. También proporcionar dinero, información sobre estrategias generales de supervivencia y apoyo emocional. A largo plazo, las redes pueden evolucionar como estrategias comunales para maximizar ingresos y evitar riesgos económicos en las sociedades de origen; velan por la existencia de un flujo renovado y constante de recursos, información y nuevos migrantes y tienden a perpetuar en el tiempo la experiencia laboral 
de los que las formaron en primer lugar, facilitando a los recién llegados trabajos semejantes.

Las redes pueden servir para amortiguar el peso que tienen sobre los migrantes los costes y la ruptura vital que supone la inmigración; determinar, hasta cierto punto, quiénes son los que emigran de las comunidades y las familias; influir en la selección de los lugares de destino y de origen; mantener los vínculos del migrante con la sociedad de origen y condicionar la integración de los migrantes en la sociedad de destino (Fabbiano, 2007; García, Gadea y Pedreño, 2010).

Nuestra premisa es que las redes existen y cobran importancia, dentro del proyecto migratorio, tanto en el trayecto como en el asentamiento; pero que, sin embargo, su uso e intensidad es tremendamente dispar y distinto, según nos refiramos a unas u otras comunidades de inmigrantes. Profundizaremos en las formas en que las utilizan en el colectivo de procedencia argelina asentado en España, a raíz de trabajos de campo desarrollados en la Comunidad Foral Navarra (España) entre los años 2002 a 2013.

\section{LLEGADA Y DISTRIBUCIÓN DE ARGELINOS EN ESPAÑA}

El número de personas de procedencia argelina residentes en nuestro país, aún con ser sólo una pequeña parte del volumen total de población de procedencia extracomunitaria asentada (en torno al 2,5\% según datos del Ministerio de Empleo y Seguridad Social), se ha mantenido estable en los últimos años. Así, la Secretaría de Estado de Inmigración y Emigración cifraba para 2014 en 57.588 las personas de procedencia argelina con permiso de residencia en España. Es una población eminentemente masculina, 65\% varones frente al 35\% mujeres. Es también una población mayormente adulta, dado que en torno al $75 \%$ es mayor de 16 años.

A tenor de las investigaciones efectuadas, la población argelina empezó a contemplar España como posible país de destino de sus proyectos migratorios en el momento en que otros países europeos como Gran Bretaña, Francia o Italia aplicaron medidas legislativas más restrictivas respecto a la llegada y asentamiento de población inmigrante, con el objetivo de disminuir sus flujos y, de forma más específica en el caso francés, evitar la llegada de argelinos implicados en acciones políticas en su país de origen.. Nuestro país mantenía en los años noventa todavía una postura muy permisiva respecto a la llegada, asentamiento y posibilidades de ocupación (en la economía más formal o la sumergida) para las personas inmigrantes, y esta permisibilidad explicaría que España se convirtiera primero en lugar de tránsito para procesos migratorios transcontinentales y paulatinamente (y ante la imposibilidad o aplazamiento de éstos) en lugar de destino y residencia estable para una parte creciente de los inmigrantes argelinos. En nuestras investigaciones no es excepcional encontrar personas argelinas que, tras años de residencia y trabajo en Alemania o Bélgica optaron por buscar trabajo y establecerse en España.

Sobre la llegada y asentamiento de esta población identificaríamos cuatro etapas:

1- Hasta 1989. La inmigración de procedencia argelina en nuestro país es casi testimonial y se produce mayormente de forma estacional; es decir, existía cierta tradición (por la proximidad geográfica y la facilidad de las comunicaciones marítimas) de que personas argelinas se desplazasen a nuestro territorio para determinados trabajos agrícolas de tipo estacional. En esos momentos la permisibilidad y la laxitud de las autoridades permitían la entrada y salida regulares del país, así que esta población raramente se 
asentaba de forma permanente en el territorio, pues, como indicábamos sus destinos migratorios tradicionales eran Francia, Gran Bretaña y, en menor medida, Estados Unidos y Canadá.

2- De 1990 a 1999. Las vicisitudes económicas, políticas y sociales argelinas ocasionan una emigración masiva del país. La población argelina, dadas las dificultades de acceso a sus países de destino tradicionales, empieza a llegar a España, primero como país de tránsito y posteriormente como país de elección; podríamos decir que encuentran en el país facilidades de regularización, trabajo y asentamiento no previstas y que esto ocasiona su permanencia e intensifica el "efecto llamada". Las personas que abandonan Argelia en este periodo $-\mathrm{y}$, por tanto, llegan en parte a nuestro país- lo hacen impulsadas más por motivaciones políticas e ideológicas que no económicas; pertenecen, en mayor grado, a sectores socioeconómicos medios y presentan un nivel de formación/estudios también medio o incluso superior.

3- De 2000 a 2009. Identificamos como principal motivación inmigratoria la económica, incentivados por la existencia de las redes familiares o relacionales con personas ya asentadas en nuestro territorio con anterioridad. En otro orden de cosas, sería en esta etapa en que se diversifica tanto por género como por nivel de formación y estudios la población argelina inmigrada y en que ésta inicia con mayor intensidad procesos de reagrupación familiar (aunque, como hemos visto, la proporción de residentes menores de 16 años y mayores de 64 años se mantiene baja, y el perfil mayoritario del inmigrante argelino continúa siendo el de varón adulto y solo).

Apuntamos, asimismo, que las dificultades de obtención de una autorización de residencia legal en el país son mucho mayores para las personas llegadas en este periodo; muchas de las personas entrevistadas con entre tres y cuatro años de estancia irregular en nuestro país manifiestan fehacientemente esta especificidad.

4- De 2010 a la actualidad. El cambio del contexto económico en España (incremento desempleo, descenso de las tasas de actividad, etc.) ha conllevado una disparidad de estrategias económicas y familiares de las personas migrantes. Así, encontramos desde personas que han iniciado nuevos movimientos migratorios hacia otros países europeos (sobretodo Francia y Alemania); personas que han iniciado desagrupamientos familiares, es decir, familias en las cuales los menores de edad han vuelto al país de origen (mayormente con la madre) mientras el padre reside en España. Esta estrategia permite reducir los costes de manutención de los menores y gastos de vivienda, en general. Aunque también encontramos grupos familiares que han decidido permanecer en nuestro país, a pesar que se encuentren en situación de desempleo y a la espera de una mejora de la situación económica (a veces para no perder el derecho a determinadas prestaciones y ayudas sociales o la expectativa de solicitar la nacionalidad).

Con todo, en 2015, los datos que ofrece la Secretaría de Estado de Inmigración y Emigración (Abril,2015) recogen, así, una situación ampliamente favorable para la población de procedencia argelina, dado que el $44,57 \%$ de la misma contaría con una autorización de residencia permanente en el país, frente al $29,77 \%$ con que cuenta, como media, el total de población extranjera. Se perfilan los efectivos llegados a nuestro país en la definida como primera etapa migratoria los que ostentarían esta singularidad (en el año 2014 de las 2.342 personas de procedencia argelina a las que les fue concedida la nacionalidad española, un 56\% contaban con más de 10 años de residencia en España y un $35 \%$ habían nacido en España). 
En referencia a su distribución dentro del Estado Español, observamos una relevancia de asentamiento en zonas consideradas más agrarias, como el sur de Andalucía, la huerta leridana (en Cataluña) y los campos del sur de Navarra.

Mostraremos sucintamente algunas de las redes detectadas y analizadas, con especial atención al caso de esta última zona.

\section{ESTRATEGIAS DE LLEGADA Y ASENTAMIENTO}

\subsection{Redes sociales desde Argelia que facilitan la emigración}

Para emigrar, serán de vital importancia los recursos previos que el sujeto posea, como particular forma de capital social (Bourdieu y Wacquant, 1992), pues van a facilitarle una serie de preparaciones e informaciones que pueden asistirle en el proceso y pueden resultar decisivas en el desarrollo de la experiencia migratoria.

En primer lugar, la elección del país de destino no es casi nunca una elección racional, entre otros factores, porque no es una decisión que dependa solamente del sujeto o que éste pueda tomar de forma totalmente libre. Las facilidades o trabas para abandonar el país de origen, las dificultades u oportunidades de entrada en el elegido/s, el dinero de que se dispone, a quién se conoce en los posibles destinos barajados, etc., pueden influir poderosamente en la decisión final. La que consideramos aquí es la decisión férrea de la partida, del deseo firme de emigrar y de la movilización por parte del sujeto de todas sus energías y red de relaciones personales (firmes, difusas o mediante terceros) para materializar ésta.

En opinión de Castles y Miller (2004), las cadenas de migración típicas se ponen en marcha por un factor externo, como el reclutamiento o el servicio militar, o por un movimiento inicial de jóvenes pioneros, por lo general hombres. Una vez que el movimiento se ha producido, lo que hacen los emigrantes sobre todo es seguir "caminos ya abiertos"; luego los ayudan familiares y amigos ya establecidos en la zona de inmigración. Más allá de los elementos económicos más o menos racionales que pesan sobre las migraciones, las razones son sociales, y son las redes creadas por el movimiento migratorio las que permiten explicar el carácter perdurable de los flujos migratorios (Parella, 2003; Lomnitz, 1994 y Sayad, 2011).

El sujeto buscará así el encuentro con personas que se hallan en el país/es que se barajan como posibles puntos de destino; pueden ser personas que directamente pertenezcan a su núcleo de relaciones de amistad o familiares o no. Es decir, no resulta inusitado que busque nuevos lazos: un primer amigo o conocido le da referencias de una tercera persona que se encuentra trabajando en el extranjero y que llegará de vacaciones; el sujeto preguntará por las referencias del domicilio de los familiares de éste en la ciudad, donde se personará para recabar unas primeras informaciones e interesarse por su venida o forma de localización.

En nuestro trabajo de campo pudimos constatar que la llegada de los barcos que arriban regularmente al puerto de Argel procedentes de Francia y España suscitan siempre gran expectación entre la población argelina; se agolpan multitud de curiosos o interesados por saber quién llega, quién le espera, qué traen (qué noticias y/u objetos traen); el emigrante potencial puede recabar allí unas primeras informaciones o buscar unos primeros conocidos con los que consultar. 
Para los potenciales migrantes todo tipo de información resulta de utilidad, las condiciones de llegada y asentamiento, la rigurosidad de los controles policiales, la existencia o no de entidades de apoyo y ayuda al recién llegado; aunque, primordialmente interesa conocer las posibilidades de una pronta inserción laboral, las condiciones de empleo y salariales, el nivel de vida, las políticas de regularización, etc.

Identificamos, así, una primera utilización de las redes en la planificación de la partida: las redes informativas; el buscar por todos los medios posibles información de todo tipo sobre el futuro país de destino, con la finalidad de contrastar la información diversa recopilada y reducir la incertidumbre y los riesgos del inicio del proyecto migratorio. Resultan tremendamente importantes, a pesar de parecer insustanciales, dado que pueden determinar el viraje hacia uno u otro destino migratorio (Gurak y Caces, 1998), aumentar las probabilidades de éxito del mismo, y sentar las bases de contactos personales a reencontrar en el país de destino.

A esta consideración Faist (1997) añadirá tres niveles de análisis:

a) el nivel macro, que atañe a factores económicos, políticos y factores de tipo cultural, demográfico o ecológico en las interrelaciones migratorias entre países.

b) el nivel meso, que atañe a las relaciones sociales que se establecen entre lugar de emisión y de recepción. Dentro de éste distingue: lazos relacionales fuertes (que son los que se establecen mayormente dentro de la familia o unidad doméstica); lazos relacionales débiles (que son de menor intensidad y circunscritos al ámbito de "la amistad" o la red de relaciones más impersonales) y lazos simbólicos (que se fundamentan en asociaciones realizadas en base a elementos étnicos o religiosos).

c) el nivel micro, en el que cabe distinguir capital humano y capital cultural, como los principales.

Así, los lazos relacionales, que escrutará y utilizará el sujeto, pueden considerarse, según la clasificación propuesta por Faist (1997), como "lazos relacionales débiles" que, en opinión de Granovetter (2003) son los más efectivos, dado que permiten acceder a mayor cantidad de información y más diversificada que si el sujeto utilizara sólo sus lazos relacionales fuertes, es decir, se circunscribiese sólo a su ámbito familiar y de amistades delimitado, en sus primeros pasos.

Aunque, recordemos que, en opinión de Hugo (1987, citado por Gurak y Caces, 1998:84) en el proceso de toma de decisiones sobre la posible emigración y, en concreto, sobre la toma en consideración de las diversas informaciones recopiladas a tal efecto por el sujeto, se entrelazan tres condiciones diferenciadas:

1- naturaleza, volumen y fuentes de la información recopilada. En este sentido existen fuentes más dignas de crédito que otras y la confianza o la afinidad mantenidas con el informante resultan también determinantes.

2- la fase del ciclo vital, la educación, el sexo y las habilidades y motivaciones del sujeto potencial migrante, en base a las cuales éste interpretará la información recibida.

3- la evaluación que realice el entorno inmediato del sujeto de la información recibida.

Las tesis de Hugo (1987) nos permiten, así, amplificar nuestro análisis y apreciar mejor cómo pueden influir en el sujeto las variadas y a veces contradictorias informaciones que pueden recabarse y cómo éstas, al ser conjugadas con la situación personal del individuo, pueden impeler a la emigración o, por el contrario, aquietarla. Así, a título de ejemplo, un cabeza de familia adulto puede sopesar de diferente forma que un joven soltero la información recibida. Y aquel que carezca de empleo puede desoír en mayor grado que un empleado (aún con bajo salario) los relatos de los emigrados sobre los sufrimientos y penalidades a acometer en las sociedades de destino. 
En otro orden de cosas, en la planificación de la futura partida, existen muchos otros aspectos a recabar, componer y acomodar. Las quimeras giran en torno a dos ámbitos principales: la familia y el dinero.

Respecto a la primera, la familia; en general, se dan dos tipos de situaciones dentro del ámbito familiar:

* El emigrante es un varón casado. Los varones casados deben prever, antes de la partida, quien va a quedarse al cuidado de la esposa e hijos menores. Según la tradición musulmana -refrendada, en parte, por la legislación argelina- las mujeres y los menores de edad no pueden proceder libremente, ni vivir sin un varón que cuide de ellos. Así, mayormente, esposa e hijos menores quedarán bajo la tutela de padres o hermanos e incluso hijos varones mayores de edad. La estrategia que constatamos como más usual es el traslado de aquellos al domicilio del que ejerce como tutor temporal (el padre o el hermano, frecuentemente).

* El emigrante es un varón soltero, éstos, por el contrario, pueden partir sin que se les exija ninguna obligación familiar; acaso, con alguna salvedad, pues, dentro de la estructura familiar tradicional argelina, el varón sí tiene la responsabilidad de cuidar de la madre o la hermana soltera -en ausencia del padre-. Por tanto, la determinación que se tome dependerá de las circunstancias y particularidades de cada unidad familiar extensa.

Así, serán las redes familiares que definimos como "fuertes" en las que el sujeto migrante se sostendrá para resolver estas primeras quimeras.

Respecto a la segunda cuestión, el dinero, la exigencia de visado para abandonar Argelia, sin duda, ha complicado o directamente truncado, los deseos de salida de muchos argelinos hacia Europa. Todos los argelinos que planean abandonar el país en la actualidad -con los que hemos trabado relación- se refieren a la falta de dinero como uno de los principales factores obstaculizadores de la partida.

El dinero necesario para costear los gastos del visado habitualmente se intenta conseguir en el marco familiar y/o mediante la venta de enseres personales.

En Argelia es una vetusta costumbre, muy arraigada entre las clases más populares, acopiar determinados bienes de valor a modo de depósito, en el ámbito doméstico, bienes que pueden venderse en el mercado ante situaciones de necesidad. La inexistencia de entidades bancarias liberalizadas en el país, junto con las incertidumbres políticas y la desconfianza tradicional que muestran los argelinos hacia las estructuras de control estatales, ha contribuido a la pervivencia de esta peculiar forma de ahorro. Tradicionalmente, uno de los objetos considerados de mayor valor son las joyas o el oro; recordemos aquí que, uno de los motivos del alto coste de los enlaces matrimoniales es que el novio debe enviar regalos a la futura esposa (normalmente joyas) y que la notoriedad de éste se basa en la calidad y cantidad (el valor monetario, en definitiva) de estos regalos. Así son mayormente las mujeres las que disponen de joyas propias o heredadas, que se consideran una salvaguarda personal/familiar ante las adversidades.

Esta es la estrategia que, de forma más usual relatan los argelinos: la venta o empeño de determinados bienes en el mercado negro, como forma más inmediata de conseguir dinero.

Es posible también recurrir al marco familiar extenso, como forma de conseguir dinero para la partida. El sujeto intentará habitualmente, acudir a los diversos miembros de su familia extensa para reunir, mediante la suma de pequeñas cantidades, el dinero necesario para costear el visado. Algunos de los informantes relatan haber utilizado esta vía, con dos variantes: el compromiso de devolver aquello recibido, una vez asentados en el país de destino, o sin que medie este compromiso en la ayuda recibida. 
Sin embargo, son muchos, ciertamente, los que relatan que, aun contando con la voluntad de colaboración de la familia, las dificultades de todos ellos para obtener liquidez monetaria eran crecientes, un signo más del nivel de empobrecimiento generalizado de las clases medias y bajas argelinas.

Si la familia no puede o no quiere ayudar económicamente al sujeto, éste inicia un periplo de peticiones de pequeñas cantidades a los amigos y conocidos (a devolver cuando su situación en el país de destino lo permita), opta por intentar ahorrar poco a poco esta cantidad de su sueldo o por intentar realizar pequeños trapicheos o compra/ventas en el mercado negro que le permitan obtener liquidez monetaria de una forma más o menos rápida.

El hecho de que resulte muy complicado y dificultoso la obtención de un crédito bancario personal en el país es una dificultad añadida en el diseño del proyecto migratorio, aunque algunos argelinos mencionan la existencia de personas que actúan como prestamistas -de forma encubierta- a los que se puede acudir para conseguir un empréstito a devolver con el pago de ciertos intereses.

Las redes familiares detectadas existen aún sin ser visibles y guardan un orden interno definido por códigos comportamentales y tradiciones que, ante una eventualidad -como, en este caso, el cuidado de determinados miembros de la unidad familiar o el préstamo de dinero- toman forma, se conglomeran y muestran su viveza y operatividad. Estas redes asumirán la función, en origen, de hacerse cargo de algunas de las responsabilidades, funciones y roles del migrante, durante su ausencia, con la misión de permitir su perdurabilidad, estabilidad y seguridad.

Igualmente señalamos que será el potencial migrante que disponga de una estructura más sólida de redes con los que están en el país de destino, el que contará con mayores oportunidades de iniciar su itinerario migratorio, pues resulta determinante la intervención de aquellos en iniciar todos los trámites burocráticos requeridos. Como señala Massey (1998), cada nuevo migrante reduce los costes y los riesgos de la migración de un conjunto de familiares y parientes, lo cual contribuye a extender el número de personas con vínculos en el extranjero. Los lazos que buscará el sujeto serán:

a) los definidos por Faist (1997) como "lazos relacionales fuertes", es decir, los circunscritos al ámbito familiar y de parentesco más próximo del sujeto.

b) la creación de nuevas conexiones relacionales. Aunque, como decíamos, las investigaciones efectuadas señalan que son las redes fuertes las que, mayormente, utiliza el sujeto para organizar la partida, observamos que, el futuro migrante, quizás impelido por las crecientes dificultades y cerrazones de los países de destino en permitir su entrada, busca el establecimiento de nuevas redes, circunstanciales, momentáneas y de uso intermitente, débiles en todo caso, que le presten la ayuda y apoyo necesario para superar las barreras legales impuestas.

\subsection{Redes que facilitan el asentamiento en el país de destino}

Lo que diferencia las comunidades transnacionales de otros agrupamientos de alcance internacional es precisamente que su origen vincula al menos a dos estados y dos grupos estatal-nacionales, esta vez enlazados en un cuerpo de interacciones e instituciones sociales comunes y un actuar colectivo que las supone. Es decir, la existencia de estas comunidades implica un marco transnacional en su propia construcción, reproducción económico-social e identidad (Portes, 2003). Así, estas comunidades reconocen un marco identitario y un proceder cultural común. El transnacionalismo está conformado por procesos moldeados, con múltiples facetas y ubicaciones, que incluyen prácticas económicas, socioculturales y 
políticas y discursos que trascienden los confines de la jurisdicción territorialmente circunscrita del estado-nación y son parte inherente de la vida cotidiana de los involucrados. Estas relaciones establecidas por los protagonistas -individuos o colectivosinvolucran el intercambio de un torbellino de recursos tanto tangibles como intangibles, que incluye gente (que emigra, vuelve a emigrar, visita su "hogar" con regularidad), recursos monetarios (inversiones comerciales, remesas familiares, ayuda humanitaria), recursos no monetarios (ideas y símbolos culturales) y apoyo u oposición política (Guarnizo, 2003b). No podremos detallar en el presente texto las estrategias de remesas (monetarias o en especie) o al trabendo (compra-venta transnacional de productos de consumo y tecnología) para no excedernos en demasía.

Nos centraremos en las estrategias que el inmigrante despliega, que busca y que construye, la información y recursos con que cuenta, en los primeros estadios de llegada y acomodo en España. Sin embargo, resulta obligada la distinción entre los que llegaron a nuestro país cuando la presencia de población argelina en España era casi testimonial (antes del año 2000); y los llegados con posterioridad a esta fecha, dado que van a contar con una red familiar y relacional mucho más formalizada que los anteriores.

\subsubsection{Los llegados antes del año 2000}

De nuestro trabajo de campo se desprende que, los primeros efectivos que llegaron, es decir, aquellos que lo hicieron en los años noventa, declaran no conocer prácticamente a ninguna persona ya asentada -“eran pocos”, numéricamente hablando- pero esto no supone ninguna dificultad, ni es visto como una contrariedad; sus movimientos dentro de nuestra geografía serán altos pero en solitario, buscando las mejores oportunidades laborales o residenciales y estableciendo amistades y lazos relacionales circunstanciales con iguales a partir de estas dos premisas. Son los "pioneros", en el sentido que le da Castles (2000).

Uno de los factores distintivos de esta primera oleada de argelinos en nuestro país es la práctica inexistencia de lazos relacionales con personas inmigrantes ya residentes, es decir, la inmensa mayoría declara no conocer prácticamente a ningún otro compatriota en el momento de su llegada; su escaso número y su dispersión en nuestra geografía dificulta esta interrelación y, por tanto, la creación de entramados organizados de ayuda.

Otro factor distintivo a señalar es la gran movilidad que la mayoría realiza en estos primeros momentos; gran parte de ellos visita Barcelona, Madrid, Valencia o Andalucía -y trabaja de forma intermitente en estos lugares- antes de su asentamiento más o menos estable en Navarra.

Señalamos, asimismo, que muchos relatan no buscar en este periplo el establecimiento de microcomunidades o redes de relación estables ni tan sólo entre sí, no parecen necesitarlas, aunque sí aparece en sus discursos una tenue identificación con personas marroquíes, con quien, dicen, estar unidos por unos ciertos lazos de hermandad, como el Islam o su condición de magrebíes. Los marroquíes, con mucha más tradición de inmigración en España y en mayor número, son vistos en este estadio como personas con las que establecer relación o algún tipo de ayuda mutua con mucha mayor facilidad que con otros colectivos.

Estos primeros argelinos asentados en España manifiestan así, mayormente, un sentido de pertinencia difuso y de baja intensidad a una comunidad genérica, casi simbólica, de inmigrantes, que es la comunidad establecida en base a rasgos étnicos o religiosos comunes, la que Faist (1997) denomina, justamente, como fundamentada en "lazos simbólicos", pues los musulmanes son "hermanos en el Islam", expresión recurrente en 
boca de muchos argelinos entrevistados. La operatividad esperada en este marco de relaciones es la de una cierta camaradería y ayuda mutua circunstancial, de reciprocidades superficiales, acontecidas en encuentros fortuitos y de baja intensidad y duración.

Abundan, en este estadio, los relatos de una sociedad de acogida amable con la inmigración, que ampara al recién llegado, le ayuda y le proporciona asistencia de una forma voluntaria y desinteresada

Los lazos relacionales que se establecerán serán mayormente circunstanciales, débiles, aleatorios y casi casuales. Era fácil encontrar un trabajo -aún en la economía sumergida- y no aparecen en los discursos competencias, fricciones o diferenciaciones con otros colectivos, ni por el trabajo ni por la vivienda; aunque difícilmente se establecen lazos duraderos, sencillamente acuden y residen allí donde existe mayor demanda de trabajo.

Con todo, evidentemente, se producen encuentros informales y fortuitos entre el colectivo y se establecen lazos de compañerismo y amistad entre individuos afines. Los locutorios y las mezquitas serán el punto de referencia por excelencia de los inmigrantes en este estadio.

Los locutorios, tanto en este momento como en la actualidad, son uno de los lugares donde acuden con asiduidad los inmigrantes, sea cual sea el lugar donde se encuentren. Dicen acudir para ponerse en contacto con sus familiares en Argelia y para establecer contactos con otras personas inmigrantes (en un sentido muy abierto) que les permiten recabar información sobre posibilidades de trabajo o vivienda, dado que, mayormente comparten, con los que mayormente frecuentan estos establecimientos, las mismas preocupaciones e inquietudes en lo referente a su estancia en España. El locutorio es, así, una pieza clave en la búsqueda y encuentro de recursos y ayudas puntuales.

El inmigrante argelino, dada su pertenencia a la cultura islámica y su conocimiento del árabe, dice acudir a la mezquita para resolver todo tipo de necesidades: desde combatir la soledad, compartir vivencias, experiencias y anécdotas; hasta asearse o pernoctar -en caso de estadía de paso-, conseguir algo de alimentos o dinero y recabar informaciones sobre el lugar, si el sujeto piensa en la posibilidad de permanecer por un tiempo.

Asimismo, durante los diversos tránsitos que los argelinos realizan por el interior del país, los flujos de información están presentes y orientan, en muchos casos, los desplazamientos internos que se realizan: se habla de dónde hay trabajo, de las condiciones del mismo en diversas partes de nuestra geografía; de amigos, parientes o conocidos que están en otros países europeos y sus condiciones de vida o trabajo, etc.

\subsubsection{Los llegados con posterioridad al año 2000}

Una primera y obligada distinción se produce, así, entre:

a) la llegada de personas que mantienen relaciones de consanguinidad con los inmigrantes ya asentados. Encontramos aquí, mayormente, la llegada de mujeres y menores de edad, fruto, en su mayoría, de peticiones de reagrupamiento familiar realizadas por los argelinos varones llegados en la etapa anterior; pero también, aunque, en menor grado, la llegada de hermanos, sobrinos, tíos, cuñados, etc., es decir, personas que llegan con un proyecto emigratorio propio pero que cuentan con una red de apoyo consolidada que, como veremos, va a facilitarles el asentamiento; es decir, cuentan con una estructura reticular basada en lazos de parentesco (Barnes, 1954).

b) la llegada de varones, mayores de edad, mayormente solteros, que llegan en solitario. Éstos, a diferencia de los anteriores, no cuentan con una red de apoyo tan sólida que prepara su llegada y les acoge pero van a beneficiarse, sin duda, de las redes de conexión y 
relación ya existentes de los coetáneos asentados en nuestro país; las redes de amistas o paisanaje que identifica Barnes (1954).

Para los primeros, la red se puede iniciar ya facilitando la partida desde el origen, dado que se puede tramitar desde España una carta de invitación para un residente en Argelia. Mayormente se utiliza para solicitar la llegada de un familiar próximo (excepto el cónyuge e hijos menores, que acceden a la residencia por la vía del reagrupamiento familiar) como hermanos, sobrinos, padres, etc. El recién llegado podrá entrar así en nuestro país con mayor facilidad y amparo legal.

De no ser posible esta modalidad, igualmente la venida del recién llegado será atendida y éste gozará desde el primer momento de una mayor malla de seguridad, amparo y protección ante las primeras vicisitudes. El llegado recibirá diversos tipos de apoyo y ayuda en un grado más avanzado, más completo y amplio de ayuda que la mera transmisión de información, dado que incluye la provisión de determinados recursos, auxilios y asistencias al nuevo emigrante. Las redes disponibles en el lugar de destino sirven como sistema de seguridad financiera, ayudan a encontrar trabajo, proporcionan alojamiento y son fuente de información de todo tipo. La red da respuesta también al conjunto de necesidades que conciernen a la dimensión expresiva; asimismo contribuyen a amortiguar el coste emocional y afectivo que supone la separación de los más allegados y del universo natural de referencia.

Así, será acogido en casa del familiar (inmigrante asentado) por un tiempo indefinido, dispondrá de la ayuda material necesaria, y podrá beneficiarse de todo el capital informacional y de recursos de que ya dispone el sujeto asentado para encontrar trabajo (en el mismo lugar de trabajo que éste o en su mismo sector de actividad o localidad) y acceder a los diversos servicios de ayuda al inmigrante existentes, sin las presiones a que se encuentran sometidos los que llegan sin contar con apoyo de redes.

Los segundos son los varones que llegan en solitario, atraídos por el efecto de unas redes informativas que relatan la existencia de muchas y positivas facilidades de incorporarse al mercado laboral español, la improbabilidad de una expulsión, las sucesivas convocatorias de regularización que facilitan la adquisición de los permisos legales y el asentamiento, etc.

Aunque denotan la existencia de redes, son redes de paisanaje, redes que, aunque ayudan a definir el proyecto migratorio y a sortear las primeras dificultades del mismo, no están fundamentadas en una trabazón de reciprocidades o lazos de ayuda fuertes y, por tanto, no estarán dispuestas a ejecutar determinadas solidaridades -como facilitar alojamiento o ayuda material- dentro del colectivo; la individualidad del itinerario seguirá siendo muy marcada.

Las redes establecidas pueden ser, por tanto, catalogadas como débiles, incompletas, discontinuas y circunstanciales, dado que el recién llegado, en muchos casos, va a tener que buscarlas y establecerlas a su llegada, que las utilizará de forma alterna según se establezca en uno u otro lugar y que, de entrada, no existe garantía de que se mantengan a lo largo del tiempo o que le proporcionen una ayuda prolongada o permanente (Suárez, 2010)

Así, centrándonos en la instrumentalizad u operatividad de los vínculos débiles en las contribuciones de las redes, consideramos que:

* En el momento de organizar la partida o salida del país de origen, quizás resulten fundamentales para el migrante las redes de parentesco (vínculos fuertes); pero a la llegada al país de destino, la existencia de redes débiles explica las diferentes trayectorias de asentamiento. De tal forma que los vínculos débiles hacen de puente sin requerir 
inversiones importantes por parte de sus miembros, por lo que acrecientan la reserva de recursos potencialmente disponibles para los sujetos. Igualmente, los vínculos débiles pueden actuar de puente entre el sujeto migrante y diversos grupos primarios $u$ organizaciones formales. De igual forma, los lazos débiles permiten una mayor extensión y mayor alcance de recursos más diversificados; resultan más útiles en contextos de incertidumbre y en tareas que implican mayor desconocimiento por parte del sujeto.

* Si las redes fuertes no se ven compensadas con vínculos débiles (en destino) es mayor la probabilidad de aislamiento respecto a segmentos amplios de la sociedad. Las redes basadas en lazos fuertes requieren para su mantenimiento una inversión considerable de tiempo y recursos emocionales por parte de los sujetos; los lazos débiles no requieren esta inversión y los sujetos pueden encaminar sus esfuerzos en aras de una mayor consecución de sus objetivos migratorios.

Se mantiene, por tanto, la coexistencia de dos situaciones diferenciadas:

* Las redes sólidas de apoyo, que incluyen la espera del recién llegado y una acogida -en el sentido amplio del término-, es decir, el recién llegado va a contar con vivienda, apoyo económico y utilización de la red informacional y de recursos de que dispone el miembro acogedor. Esta posibilidad, como venimos diciendo, sólo es atribuible a una pequeña parte de los recién llegados, normalmente familiares de primer grado de los ya asentados.

* Las redes débiles de apoyo. Aquellos que llegan se beneficiarán de todo tipo de informaciones que circulan, tanto en el país de origen como aquí, dada la mayor proporción de personas argelinas asentadas. Asimismo, se beneficiarán de la existencia de comunidades ya establecidas y organizadas de personas argelinas -o magrebíes- que podrán proporcionarles diferentes tipos de orientaciones y recursos puntuales.

\subsection{Redes relacionales en base a las creencias religiosas}

Distinguimos, en nuestro trabajo de campo dos tipos de entidades constituidas por las personas con creencias religiosas, en este caso musulmanas.

3.3.1. La primera se construirá en base a la mezquita, lugar de culto y de oración pero que, realizará, en los primeros momentos de asentamiento, y, a falta de otro tipo de entidad asociativa, funciones de agrupación y encuentro de la microcomunidad.

En el caso concreto de la ciudad de Tudela (Navarra), un pequeño grupo de varones musulmanes, argelinos y marroquíes inició en 1992 negociaciones con el Ayuntamiento de Tudela, éste accede a cederles en uso un local de propiedad municipal, que habilitan para realizar funciones de mezquita. Rápidamente, la comunidad musulmana, especialmente los argelinos, pero también marroquíes, empieza a organizar su vida social, cultural y lúdica entorno a esta mezquita; es decir, empieza a organizar su vida social, cultural y lúdica entorno a los valores islámicos.

Cabe destacar que, en un primer momento la comunidad no se dota de una personalidad jurídica ni se institucionaliza como entidad cultural o recreativa; sencillamente, se agrupan entorno al edificio diversas personas que comparten la fe musulmana y van acordando por mayorías, y sin liderazgos claros, sus diversas actuaciones, aunque actualmente es, formalmente una asociación.

Desde el primer momento la comunidad perseguirá su autofinanciación y, en este sentido, se recaudarán entre sus miembros aportaciones económicas voluntarias; también en los diversos comercios frecuentados por musulmanes se instalarán "botes" donde depositar contribuciones. Los fondos recaudados se utilizan para financiar las diversas 
actividades y costear los servicios del imán, dado que éste subsiste exclusivamente de las actividades que se realizan en la mezquita.

Con la llegada paulatina de esposas e hijos la comunidad crece y se diversifican las actividades, para integrar en la misma a todos los afines. De este modo la mezquita empezará a realizar funciones de:

1) Relación. El imán se erige como la máxima autoridad en cuanto a normas de comportamiento y relación entre sus miembros, de acuerdo a los principios del Islam. Con el objetivo de fortalecer los lazos y el sentimiento de comunidad entre sus miembros, y ocupar el tiempo de ocio disponible, se organizarán también excursiones familiares de fin de semana a la sierra, campamentos infantiles, clases de árabe y enseñanza del Islam, etc. Asimismo, en aras de fortalecer la pertenencia a una comunidad islámica, en sentido genérico, se propiciará el contacto con otras comunidades musulmanas existentes en el estado español y se intensifican las redes y relaciones de contacto entre las mismas; así algunos musulmanes la zona sur de Navarra empiezan a asistir a los encuentros religiosos multitudinarios que se organizan, alternativamente, en diferentes partes del estado y los niños asistirán a campamentos infantiles que se organizan a nivel estatal, en los que algunas jóvenes y madres de familia ejercerán como monitoras.

2) Asistencia. El Corán indica como obligación de todo musulmán el dar limosna a los pobres, es decir, ayudar a los necesitados de la comunidad. Así, forma parte de la costumbre, que los fieles que acuden a una mezquita donen limosna, denominada "zakat". Así, este imán, con este fondo, organizará alrededor de la mezquita una verdadera red de ayuda y contacto entre los musulmanes que participaban en la misma y aquellos que, ocasionalmente, se encontraban en la ciudad. Mayormente se destina a mitigar situaciones de emergencia o necesidad entre sus miembros (un viaje de urgencia al país de origen por motivos familiares, una enfermedad, la compra de determinados enseres, etc.) persiguiendo siempre que es posible la devolución de este préstamo; también organiza la repatriación de difuntos al país de origen (mediante una entidad aseguradora), cuestión a la que los musulmanes conceden gran importancia, dada la dificultad de realizar entierros en la ciudad según la prescripción coránica.

3) Información. La mezquita, en este marco de relaciones, va a funcionar ineludiblemente como gran centro emisor y receptor de todo tipo de informaciones. Los sujetos que a ella acuden en las horas del rezo, en las horas libres, los días festivos, etc. (mayormente varones) exponen y comentan todo aquello que atañe a sus vidas: los que han visitado Argelia traen noticias y novedades sobre el país, sobre las condiciones de trabajo en los distintos lugares, sobre vicisitudes y experiencias de regularización, sobre la familia (de aquí y de allí), sobre el mercado de la vivienda, dónde preguntar, cómo hacer, etc. La certeza de pertenecer a una comunidad -la musulmana- que implica el compartir unos valores morales y sociales propios y comunes, invita a la confianza, el compañerismo y la ayuda mutua entre iguales, frente a una sociedad que, en su conjunto, reconocen como hostil.

De alguna forma, cuando la identidad cultural está revestida de unas creencias religiosas (que en el caso del Islam constituyen una auténtica cosmovisión y forma de vida), el vínculo entre el individuo y su comunidad de semejantes se convierte en vehículo fundamental de la acomodación (Harper, 2004:448). Así, la búsqueda de fórmulas que permitan la reproducción de vínculos comunitarios y la reconstitución de referencias y prácticas que resultan de vital importancia en el individuo y/o grupo familiar explican su aglutinación entorno un espacio que pueda ser utilizado con esta finalidad. 
Para Moreras (2004) y Tarrés y Salguero (2010) la creación de mezquitas en Europa se convierte en una forma mediante la cual los sujetos pueden reestructurar el orden propio de la sociedad de origen y hacer frente a la acción aculturadora de la de acogida.

La mezquita realiza, por así decirlo, una doble función, dado que más allá de su función como espacio de culto, es el espacio que estructura socialmente la comunidad musulmana, una expresión visible de su identidad colectiva; el lugar, por tanto, donde confluye (y se entremezcla) religión e identidad comunitaria. El espacio compartido permite a la comunidad tomar conciencia de sí misma, mostrar su existencia al resto de la población y manifestar abiertamente el cumplimiento de sus creencias y preceptos.

Así, en opinión de Moreras (2002:209) la mezquita incluye un triple sentido, desde un punto de vista identitario:

a) de vinculación con el conjunto de la comunidad musulmana en general (la umna).

b) como uno de los puntos de referencia colectiva de la comunidad local y de la población itinerante -o de paso- que profesa esta creencia.

c) ante la sociedad no musulmana en la que nace este nuevo espacio.

En el caso de la mezquita de Tudela resultan identificables las tres distinciones:

a) su existencia, bajo la forma legal de asociación, ha permitido a sus miembros establecer y mantener un contacto con el resto de comunidades musulmanas existentes en el territorio español e iniciar actividades conjuntas, de mayor alcance y envergadura, como la asistencia a espacios de oración y retiro espiritual convocados a escala nacional, la asistencia de sus miembros más jóvenes a campamentos de verano organizados también a escala nacional, preparación conjunta del hayy (peregrinaje a los lugares santos de La Meca) desde España, etc.

b) su enclave resulta el punto indiscutible de referencia para la comunidad de creyentes no sólo del municipio, sino también de toda el área de influencia que conforma la zona de La Ribera navarra; asimismo, reciben y dan cobijo y ayuda a musulmanes que se encuentran de paso por la región o que se establecen en ella por periodos cortos.

c) la visibilidad de las prácticas y ritos asociados a la religión musulmana se ve incrementada, sin duda, ante el resto de la población con la existencia de este enclave; dado que, por una parte, el número de efectivos que se concentran en su interior o ante sus puertas en las horas de oración puede ser elevado y que, por otra, para la celebración de determinadas fiestas de especial significación religiosa (como el fin del ramadán, la fiesta del cordero) o la celebración de determinados actos sociales (como los cumpleaños infantiles) se utiliza la pequeña explanada al aire libre existente en el exterior del local.

3.3.2. Sin embargo, a medida que el número de población con creencias musulmanas crece y su afianzamiento sociocultural en el territorio es mayor, las aspiraciones y exigencias de esta comunidad se diversifican y encontramos, en un segundo momento, el nacimiento de diversas asociaciones culturales que persigue, aun partiendo de una raíz religiosa, quizás una mayor apertura con la sociedad de acogida y el mostrar, más allá del cumplimiento de la fe religiosa, otras manifestaciones socio-culturales de sus pautas de vida, a la vez que el poder realizar actividades de signo más amplio y un tanto alejadas del lugar de culto (la mezquita).

Resulta curioso señalar que, en uno de los casos, van a ser las mujeres las que, inicialmente, promoverán la creación de esta asociación y perseguirán el disponer de un espacio de encuentro propio, que les permita desarrollar actividades más acorde a sus intereses e inquietudes lúdico-formativas. Indicar, asimismo que, desde su nacimiento estas asociaciones han buscado su consolidación, tanto en el terrero local (mediante la 
participación en encuentros de asociaciones más generales, mesas para la integración, actos lúdicos y culturales), como en el supralocal (formando parte de redes asociativas de cariz estatal y supraestatal) manteniendo siempre su voluntad de participar de la vida cultural y social de la comunidad de destino pero dando a conocer sus singularidades culturales y religiosas. En todo caso, significa un paso decidido hacia la normalización y diversificación de la construcción de redes sociales en un espacio social concreto.

\section{REFLEXIONES FINALES}

Las migraciones son un importante motor de cambio, tanto en las sociedades de origen como en las de destino, y entre otras cosas, ese cambio se produce por la construcción de estas nuevas redes sociales, muchas de ellas con una fuerte dimensión transnacional. El capital social del migrante es un elemento especialmente relevante en el éxito de su proyecto migratorio. Los recursos relacionales, de amigos, familiares y conocidos que componen su particular red relacional, pueden resultar determinantes en la consecución de sus proyectos migratorios y de su asentamiento en destino. En relación a la efectividad y densidad de las redes, se puede constatar que, tanto para organizar la partida como para favorecer el proceso de instalación y asentamiento, lo que presenta mayor efectividad es la combinación entre redes fuertes, (preferentemente de tipo familiar), y redes débiles, de base comunitaria. El tipo de relaciones identificadas en destino tienen un carácter más casual (encuentros), basados en la identidad nacional o en la religión y con finalidad de ayuda mutua o sentirse entre iguales, que otras finalidades, más instrumentales o utilitarias. Es necesario tener muy presente que los procesos migratorios que analizamos se encuentran en una fase que podríamos identificar como embrionaria o muy elemental. Esto hace que todavía no se haya desarrollado plenamente el proceso de transnacionalismo, con sus múltiples ramales, muy estudiado, por ejemplo, en sociedades con gran tradición inmigratoria, como la de Francia, Holanda o los EEUU. Por tanto, por el momento, la importancia de las redes transnacionales como factor determinante tanto en la elección de destino, como en las facilidades de asentamiento, debe ser matizada; dado que los lazos establecidos entre origen y destino se mantienen débiles (debido a lo reciente del fenómeno migratorio), siendo las variables legales y políticas las que mantienen preponderancia.

Con todo, seguimos a Portes (2001) al considerar que el fenómeno merece especial atención por diversas razones:

a) La primera es que, aunque en la actualidad es limitado numéricamente, tenemos fundadas razones para esperar que crezca en el futuro. Al respecto deberíamos notar que su excepcionalidad presente se refiere a la proporción relativa de aquellos que participan regularmente, no a su número absoluto. Ya hay miles y miles de inmigrantes y sus contrapartes que en sus países de origen han organizado empresas trasnacionales, se han movilizado para la acción política o trasformado el carácter de las formas culturales y religiosas locales mediante sus continuos intercambios de ida y vuelta. En el futuro, es de esperar una expansión significativa del número y del alcance de estas actividades, porque el trasnacionalismo de los inmigrantes no responde a razones ideológicas, sino a la lógica misma del trasnacionalismo global.

b) La segunda razón es que puede alterar de varias maneras el proceso de integración en la sociedad de recepción de los inmigrantes de primera generación y de su descendencia. Una 
posibilidad es que los empresarios trasnacionales exitosos vuelvan a casa y lleven a sus familias consigo. Una práctica común entre los inmigrantes que consiste en invertir en tierra y en hogares de retiro en sus comunidades de origen apunta en esta dirección, aunque no hay hasta el presente evidencia firme de cuál sea la proporción que efectivamente regresa de manera permanente. Existe una posibilidad más intrigante: que las actividades trasnacionales en realidad acompañen y sostengan una adaptación exitosa en la sociedad de acogida.

c) La tercera razón yace en sus efectos sobre el desarrollo de los países de emigración. Los gobiernos de los países de origen han procurado en años recientes intensificar sus contactos con sus respectivas diásporas y fomentar la participación de sus emigrados en la vida nacional de distintas maneras. Muchos países han promulgado leyes de ciudadanía y nacionalidad duales para los emigrantes; se han otorgado derechos de voto en las elecciones nacionales a los expatriados, y algunos gobiernos incluso han indagado maneras de asegurar a las comunidades de emigrados la representación en las legislaturas nacionales. Además, varios de estos gobiernos han establecido agencias y programas en el exterior orientados a sus emigrantes y a proporcionales diversos servicios.

$\mathrm{Su}$ estudio resulta de utilidad también para futuras iniciativas de codesarrollo bilaterales.

\section{BIBLIOGRAFÍA}

ANDERSON, B. (1993). Las Comunidades imaginarias. México: Fondo de Cultura Económica.

APPADURAI, A. (2002). La modernidad desbordada. Dimensiones culturales de la globalización. Buenos Aires: Trilce.

BARNES, J. (1954). "Class and Committees in a Norwegian Parish Island", Human Relations, 12:743.

BOURDIEU, P. y WACQUANT, J.D. (1992). An invitation to reflexive sociology. Chicago: The University of Chicago Press.

CASTLES, S. y MILLER, M. (2004). La era de la migración. Movimientos internacionales de población en el mundo moderno. Méjico: Universidad Autónoma de Zacatecas.

DIETZ, G. (2003). Multiculturalismo, interculturalidad y educación: Una aproximación antropológica. Granada: Universidad de Granada.

FABBIANO, G. (2007). "Les descendants d'immigrés algériens et les descendants de harkis au minoir de la terre perdue", en C. Audebert y E. Ma Mung (eds.) Les migrations internationales: enjeux contemporains et questions nouvelles. Bilbao: Universidad de Deusto, pp. 197-209.

FAIST, T. (1997). "The Crucial Meso-level", en T. Hammer y T. Faist Internacional Migration, Immobility and Development. Oxford: Berg, pp. 187-217.

GARCÍA CANCLINI, N. (1989). Culturas híbridas, estrategias para entrar y salir de la modernidad. México: Grijalbo.

GARCÍA, A.; GADEA, M. y PEDREÑO, A. (2010). Tránsitos migratorios: contextos transnacionales y proyectos familiares en las migraciones actuales. Murcia: Universidad de Murcia.

GRANOVETTER, M.S. (2003). "La fuerza de los lazos débiles. Revisión de la teoría reticular", en F. Requena Santos Análisis de redes sociales. Orígenes, teorías y aplicaciones. Madrid: CIS, Colección Monografias 198, pp. 196-230.

GUARNIZO, L.E. y SMITH, M.P. (1999). "Las localizaciones del transnacionalismo”, en G. Mummert (ed.) Fronteras fragmentadas. Zamora, Mitch: Colegio de Michoacán, pp. 87-112.

GUARNIZO, L.E., et al. (2003a). "La migración internacional: una perspectiva colombiana", en A. Portes; L. Guarnizo y P. Landolt (coords.) La globalización desde abajo: trasnacionalismo inmigrante y desarrollo. La experiencia de Estados Unidos y América Latina. México: FLACSO, pp. 277-314.

GUARNIZO, L.E., et al. (2003b). "Desconfianza, solidaridad fragmentada y migración transnacional: los colombianos en la ciudad de Nueva York y Los Ángeles", en A. Portes; L. Guarnizo y P. Landolt 
(coords.) La globalización desde abajo: trasnacionalismo inmigrante y desarrollo. La experiencia de Estados Unidos y América Latina. México: FLACSO, pp. 233-275

GURAK, D. y CACES, F. (1998). "Redes migratorias y la formación de sistemas de migración”, en G. Malgesini (comp.) Cruzando fronteras. Migraciones en el sistema mundial. Madrid: Fundación Hogar del Empleado, pp. 75-112.

HARVEY, D. (1991). The Condition of Posmodernity. Cambridge, MA: Blackwell.

KASTORYANO, R. (2000). "Asentamiento, comunidades transnacionales y ciudadanía". Revista Internacional de Sociología, 165:58-63.

KHACHANI, M. (2004). "La cuestión migratoria en las relaciones euromagrebíes", en G. Aubarell y R. Zapata (eds.) Inmigración y procesos de cambio. Barcelona: Icaria, pp. 105-132.

LOMMNITZ, P.A. (1994). Redes sociales, cultura y poder: ensayos de antropología latinoamericana. México: FLACSO.

- (2003). "Globalización, economía informal y redes sociales”, en J. L. García y A. Barañano (coords.) Culturas en contacto. Encuentros y desencuentros. Madrid: Ministerio de Educación, Cultura y Deporte, pp. 129-146.

MASSEY, D. (1990). "Social structure, households strategies and the cumulative causation of migration". Population Index, 56:3-26.

- (1998). "Una evaluación de la teoría de la migración internacional: el caso de América del Norte", en G. Malgesini (comp.) Cruzando fronteras. Migraciones en el sistema mundial. Madrid: Fundación Hogar del Empleado, pp. 189-264.

MORERAS, J. (2002). "Lógicas divergentes, configuración comunitaria e integración social de los colectivos musulmanes en Cataluña”, en J. de Lucas y F. Torres (eds.) Inmigrantes: ¿cómo los tenemos? Algunos desafios y (malas) respuestas. Madrid: Talasa, 196-217.

- (2004). "La religiosidad en el contexto migratorio: pertenencias y observancias", en B. López García (coord.) Atlas de la inmigración marroquí en España. Madrid: Universidad Autónoma de Madrid, pp. 410-417.

MUMMERT, G. (1999). "Juntos o desapartados: migración transnacional y la fundación del hogar", en G. Mummert (ed.) Fronteras fragmentadas. Zamora, Mitch: Colegio de Michoacán, pp. 451-473.

PARELLA, S. (2003). Mujer, inmigrante y trabajadora: la triple discriminación. Barcelona: Anthropos.

PORTES, A. (2001). "Debates y significación del transnacionalismo de los inmigrantes". Estudios Migratorios Latinoamericanos, 49: 469-486.

- (2003). "Hacia un nuevo mundo. Los orígenes y efectos de las actividades trasnacionales", en A. Portes; L. Guarnizo y P. Landolt (coords.) La globalización desde abajo: trasnacionalismo inmigrante y desarrollo. La experiencia de Estados Unidos y América Latina. México: FLACSO, pp. 377-397.

ROBERTS, B.; FRANK, R. y LOZANO-ASCENCIO, F. (2003). "Las comunidades migrantes transnacionales y la migración mexicana a Estados Unidos", en A. Portes; L. Guarnizo y P. Landolt (coords.) La globalización desde abajo: trasnnacionalismo inmigrante y desarrollo. La experiencia de Estados Unidos y América Latina. México: FLACSO, pp. 45-87.

SASSEN, S. (2003). Los espectros de la globalización. Buenos Aires, Fondo de Cultura Económica de Argentina S.A.

- (2005). Contrageografías de la globalización. Género y ciudadanía en los circuitos transfronterizos. Madrid: Traficantes de sueños.

SAYAD, A. (2011). La doble ausencia: de las ilusiones del emigrado a los padecimientos del inmigrado. Barcelona: Anthropos.

SID AHMED, A. (2004). "Migraciones y desarrollo en el Mediterráneo: lecciones y perspectivas a la luz del acuerdo de Barcelona”, en G. Aubarell y R. Zapata (eds.) Inmigración y procesos de cambio. Barcelona: Icaria, pp. 57-104.

SØRENSEN, N. (2005). “Globalización, Género y Migración Transnacional”, en A. Escrivá y N. Ribas (eds.) Migración y Desarrollo. Madrid: Publicaciones del Consejo Superior de Investigaciones Científicas, pp. 87-109. 
SUÁREZ, L. (2010). La perspectiva transnacional en los estudios migratorios. Génesis, derroteros y surcos metodológicos, en J. Lacomba y F. Palomir (eds.) De las migraciones como problema a las migraciones como oportunidad. Madrid: La Catarata, pp. 183-206

TARRÉS, S. y SALGUERO, O. (2010). "Musulmanes en Andalucía”, en R. Briones (coord.) ¿Y (tú) de quién eres? Minorías religiosas en Andalucía. Barcelona: Icaria-FPC, pp. 289-347

TARRIUS, A. (2004). "Más allá de los estados-nación: sociedades, culturas y redes de emigrantes en el mediterráneo occidental", en G. Aubarell y R. Zapata (eds.) Inmigración y procesos de cambio. Barcelona: Icaria, pp. 305-318.

VERTOVEC, S. (2003). "Concebir e investigar el transnacionalismo", en A. Portes; L. Guarnizo y P. Landolt (coords.) La globalización desde abajo: trasnacionalismo inmigrante y desarrollo. La experiencia de Estados Unidos y América Latina. México: FLACSO, pp. 353-376.

WALLERSTEIN, I. (1974). The modern World System. Capitalist Agriculture and the Origins of the European World Economy in the Sixteenth Century. Nueva York: Academic Press.

WIHTOL DE WENDEN, C. (2004). "Las migraciones internacionales en el diálogo euromediterráneo", en G. Aubarell y R. Zapata (eds.) Inmigración y procesos de cambio. Barcelona: Icaria, pp. 161-176.

\section{Breve currículo:}

\section{Anna Mata Romeu}

Doctora en Sociología por la Universidad de Lérida. Profesora Titular del Departamento de Geografía y Sociología en la Universidad de Lérida. Líneas de investigación principales: los procesos de inclusión/exclusión social, estudios sobre la desigualdad en las sociedades desarrolladas y las migraciones internacionales (transnacionalismo, redes sociales, asociacionismo inmigrante e integración en el ámbito educativo, entre otros). También ha coordinado diversos proyectos de cooperación internacional y transferencia de conocimiento relacionados con el Magreb. 